\title{
Cultural logics of emotion: Implications for understanding torture and its sequelae
}

\author{
Laurence J. Kirmayer, * Lauren Ban**, James Jaranson, ***
}

\section{Key points of interest:}

- Moral emotions, like shame, guilt, or humiliation reflect cultural systems of meaning that are used to inflict damage in torture and that must be renegotiated in the process of recovery.

- Emotions involve bodily and social processes that are based on cultural models, social scripts and scenarios; much of this knowledge is tacit or implicit and emerges in response to specific cultural affordances that depend on social context.

- Exploring the cultural meaning of emotions for survivors of torture in both their original and current social contexts can contribute to clinical assessment and the design and delivery of interventions.

\footnotetext{
Abstract

This paper explores the significance of cultural variations in emotion for the meaning and impact of torture, focusing

^) Division of Social \& Transcultural Psychiatry, McGill University

$\star \star)$ Victorian Counselling and Psychological Services (VCPS), Melbourne

$\star \star \star)$ Emeritus Faculty, University of Minnesota Medical School

Correspondence to: laurence.kirmayer@mcgill.ca
}

on the dynamics of shame, humiliation, and powerlessness. Forms of physical and psychological pain and suffering share some common neurobiological pathways and regulatory systems that are influenced by social and cultural factors. All forms of torture follow an affective logic rooted both in human biology and in local social and cultural meanings of experience. Understanding the impact of specific forms of torture on individuals requires knowledge of their learning histories, and of the personal and cultural meanings of specific kinds of violence. Exploring cultural meanings requires attention to over-arching discourse, embodied practices, and everyday engagements with an ecosocial environment. Restitution, treatment and recovery can then be guided by knowledge of cultural meanings, dynamics, and strategies for coping with catastrophic threats, injury, humiliation, helplessness and loss.

Keywords: torture, shame, humiliation, cultural variations in emotion, treatment, recovery

\section{Introduction}

In this paper, we explore the significance of cultural variations in emotion for our understanding the nature of torture. Our aim is to show how a contemporary ecosocial approach to cultural 
neurophenomenology can inform theory and practice (Kirmayer, 2015). In particular, we draw from recent work in embodied and enactive cognitive science, which suggests new ways of thinking about the interactions of culture and biology in experience (Kirmayer \& Ramstead, 2017). We do not focus on specific cultural examples because of the risk of creating misleading stereotypes. Instead, we illustrate a general approach to cultural meaning through discussion of the role of moral emotions, particularly shame, in the dynamics of torture. We want to argue for the utility of an approach to cultural variations in emotional experience that can both help to explain the mechanisms of suffering in torture and point the way toward new strategies of assessment and intervention that foreground social context.

The term "culture", in this discussion, stands for all of the humanly constructed and transmitted knowledge, institutions, and practices that constitute a way of life. Culture shapes experience developmentally, laying down learned associations, habits, skills, and automatic patterns of perception and dispositions to respond. Across the lifespan, cultural influences continue to organize experience both from the top down, through discursive practices that provide narratives for experience and, from the bottom up, through body practices that shape how we carry ourselves and respond to the physical presence of others and the environment. Culture is transmitted not only through explicit talk about mind, self and person, moral codes and the meaning of actions, experiences and events, but also through social and environmental affordances - cues and possibilities for perception and action present in particular life worlds and social niches. A major part of culture is learning how to attend to, interpret and act on these humanly constructed contexts (Ramstead et al., 2016). Much of this involves regimes of shared attention that allow cooperative action. Hence, we approach culture as situated meaning and practice.

Torture manipulates, attacks and deconstructs the familiar cultural contexts of everyday life, substituting one that is chaotic and unpredictable. In so doing, it acts to dismantle the individual's sense of self, coherence, and community, which is based on ongoing participation in a shared and predictable social world (Breyer, 2017). Yet, before, during, and after the experiential ruptures of torture, individuals use all the resources of culture to make sense of suffering and reconstruct their lives. A cultural perspective that emphasizes the social embedding and meaning of emotions, trauma and suffering can thus explicate crucial dimensions of the phenomenon of torture. Indeed, recognizing these dimensions may be essential to engage clients in treatment and address the full range of their concerns.

\section{Torture and the nature of suffering}

Torture occurs in very different social contexts, is directed against people from diverse backgrounds, and varies in ways that reflect cultural differences in values, coping strategies, sense of self and personhood. While some theories portray the response to torture as biologically fixed and determined (whether as the response to intense pain, conditioned fear, or loss of control), a cultural perspective insists that structures of meaning and social practices reach down into the body to shape experience from its inception. Although pain and fear are universal responses to injury and the threat of injury, their relationship to suffering is complex and mediated by meaning and context (Kirmayer, 2008). Forms of physical and psychological pain and suffering share 
some common neurobiological pathways and regulatory systems (Eisenberger, 2015), but these are influenced by cultural factors both developmentally and through current social contexts. Thus, both the experience of pain and fear during torture and their long-term effects are shaped by culture (Kirmayer, Kienzler, Afana, \& Pedersen, 2010).

Trauma-related distress covers a broad domain of symptoms and suffering, but much clinical research on torture has emphasized the diagnostic construct of post-traumatic stress disorder (PTSD). The construct of PTSD reflects universal patterns of responding to trauma but joins together multiple components in ways that have been determined by a history of social and cultural practices as well as political and economic considerations (Kirmayer, Lemelson \& Barad, 2007; Young, 1995). DSM-5 describes the behavioral symptoms of PTSD in terms of four clusters: re-experiencing; avoidance; negative cognitions and mood; and arousal (American Psychiatric Association, 2013). Considerable cultural variability can be found in each of these clusters along with specific symptoms of trauma-related stress (Hinton \& Lewis-Fernandez, 2011).

The appeal of PTSD has been both its fit with common patterns of experience and its link to a large body of research on conditioned fear responses in animals and humans (Kirmayer, Lemelson \& Barad, 2007). However, the picture of trauma response in PTSD, and the focus on fear do not capture the full range of impacts of torture, which commonly occur in settings of social disruption and massive human rights abuses (Bolton, et. al., 2012; McGregor et al., 2016; Tay et al. 2015, 2016; Sales, 2016) and a broader view of trauma-related distress is needed (Kagee \& Naidoo, 2004). Exposure to torture and massive violence can have consequences that go beyond fear-related responses to include persistent distress associated with shame and guilt, as well as depression-all of which may contribute to disability and dysfunction (Lee, Scragg, \& Turner, 2001; Somasundaram, 2008; Steel et al., 2009; Tol et al., 2007; van Ommerren et al., 2001; Wilson, Droždek \& Turkovic, 2006).

Based on clinical observations and field research, Silove provided a broader picture of the potential consequences of torture and massive human rights violations in terms of five biosocial adaptive systems, involving: attachment and social bonds; safety or security; social identity or role; justice and human rights; and existential meaning (Table 1) (Silove, 1999, 2007; Kirmayer et al., 2010); Tay et al., 2015). These systems span individual psychological and social processes so that the framework may be thought of as ecosocial as well as biobehavioral. Each of these adaptive systems is associated with particular emotions which are exacerbated by the torture experience and which unfold in specific social and cultural contexts.

Attachment and social bonds. Torture may deliberately target social bonds, making the individual feel an intense sense of isolation, loss, and abandonment. We depend on stable attachments to others for emotional sustenance and self-regulation not only early in development but across the lifespan. Social support and solidarity through interpersonal processes have a complex relationship to trauma response and recovery (Maerker \& Horn, 2013). However, there is evidence that social support can mitigate risk for post-traumatic depression and other trauma-related symptoms (Brewin, Andrews $\&$ Valentine, 2000; Johansen et al, 2007; Johnson \& Thompson, 2008; Ozer et al., 2003; Porter \& Haslam, 2005; Shalev, 2007). 
Table 1: Adaptive systems affected by torture

\begin{tabular}{|c|c|c|c|c|}
\hline $\begin{array}{l}\text { Adaptive } \\
\text { System }\end{array}$ & Threats & $\begin{array}{l}\text { Emotional } \\
\text { Reactions }\end{array}$ & Psychopathology & Interventions \\
\hline Attachment & $\begin{array}{l}\text { Separation from } \\
\text { significant others, } \\
\text { and culture }\end{array}$ & $\begin{array}{l}\text { Anxiety } \\
\text { Grief } \\
\text { Home sick- } \\
\text { ness Nos- } \\
\text { talgia }\end{array}$ & $\begin{array}{l}\text { Anxiety } \\
\text { Depression } \\
\text { Complicated grief }\end{array}$ & $\begin{array}{l}\text { Re-connection with loved } \\
\text { ones } \\
\text { Mourning } \\
\text { Creation of new bonds } \\
\text { Membership in social } \\
\text { groups } \\
\text { Recreating community } \\
\text { systems }\end{array}$ \\
\hline Security & $\begin{array}{l}\text { Uncertainty } \\
\text { Loss of control }\end{array}$ & $\begin{array}{l}\text { Anxiety } \\
\text { Insecurity } \\
\text { Hypervigi- } \\
\text { lance }\end{array}$ & $\begin{array}{l}\text { Anxiety } \\
\text { PTSD }\end{array}$ & $\begin{array}{l}\text { Re-assert control over } \\
\text { self and environment }\end{array}$ \\
\hline Identity/Role & $\begin{array}{l}\text { Loss of social and } \\
\text { occupational roles } \\
\text { and status } \\
\text { Misrecognition, } \\
\text { identity }\end{array}$ & $\begin{array}{l}\text { Powerless- } \\
\text { ness, shame } \\
\text { and humili- } \\
\text { ation }\end{array}$ & $\begin{array}{l}\text { Suicidality } \\
\text { Role confusion }\end{array}$ & $\begin{array}{l}\text { Recognition of status and } \\
\text { identity } \\
\text { Opportunities for mean- } \\
\text { ingful action } \\
\text { Family interventions } \\
\text { Community membership } \\
\text { Human right protection } \\
\text { Social security }\end{array}$ \\
\hline Justice & $\begin{array}{l}\text { Sense of injustice, } \\
\text { arbitrary violence } \\
\text { Impunity }\end{array}$ & $\begin{array}{l}\text { Anger, Hos- } \\
\text { tility } \\
\text { Lack of trust } \\
\text { Resentment } \\
\text { Bitterness }\end{array}$ & $\begin{array}{l}\text { Traumatic anger } \\
\text { Paranoia }\end{array}$ & $\begin{array}{l}\text { Engagement } \\
\text { Trust redevelopment } \\
\text { Family trust redevelop- } \\
\text { ment } \\
\text { Truth and reconciliation } \\
\text { Human rights protection }\end{array}$ \\
\hline $\begin{array}{l}\text { Existential } \\
\text { Meaning }\end{array}$ & $\begin{array}{l}\text { Loss of sense } \\
\text { of coherence, } \\
\text { purpose, and hope } \\
\text { for future }\end{array}$ & $\begin{array}{l}\text { Search for } \\
\text { meaning }\end{array}$ & $\begin{array}{l}\text { Alienation } \\
\text { Disengagement } \\
\text { Crisis of faith } \\
\text { Transgenerational } \\
\text { transmission }\end{array}$ & $\begin{array}{l}\text { Testimonial approach, } \\
\text { telling one's story } \\
\text { Re-engagement in life } \\
\text { projects } \\
\text { Linking with culture, } \\
\text { community and } \\
\text { religious traditions } \\
\text { Political activism }\end{array}$ \\
\hline
\end{tabular}

Adapted from Silove (1999, 2007), Ekblad \& Jaranson (2004), and Kirmayer, Rousseau \& Measham (2010)

Safety and security. Torture exposes individuals to inescapable threat, fear, pain and injury in ways that are designed to make the victim feel intensely vulnerable and powerless. Survivors may endure continuing threats to their own physical safety or that of their families due to economic stress, material deprivation, or proximity to their torturers, who may continue to hold power and have impunity from prosecution. The lack of safety in refugee camps and other transitional settings can contribute to torture survivors' distress and impaired functioning (Miller 
\& Rasmussen, 2010). Asylum seekers may experience detention under harsh conditions and prolonged uncertainty about their future-all of which compound the disruption of security from torture (Silove, Austin \& Steel, 2007).

Identity and Social Role. Torture often involves systematic attacks on the identity of the person and their social and moral status within the community, undermining a sense of purpose, value and esteem. Many forms of torture, like rape, explicitly aim to damage or destroy the person's social standing or "face." Shame and humiliation are key emotional mediators of this process of abjection, which are shaped by cultural norms of honor, recognition, and respect. In effect, the stigma attached with the experience of torture, rape and denigration of identity undermines survivors' control over their own social identity and self-presentation.

fustice and human rights. The arbitrary or capricious way that torture is meted out may contribute to intense and persistent feelings of anger at injustice, but this is mediated by the meanings ascribed to the situation (Batson, Chou \& Givens, 2009; Wemmers \& Manirabona, 2014; Tay et al., 2015). There are universal expectations for a just world and forms of restorative justice aim at re-establishing this moral order for individuals and communities (Mendeloff, 2009). However, notions of justice and fairness vary with different social, moral and political systems (Avruch, 2010; Hatfield \& Rapson, 2005). Cultures that accept specific types of hierarchy and gender roles may differ in what they consider unjust for specific classes or categories of people and may sanction violence as a way to restore honor and social equity (Fiske \& Rai, 2015; Ignatieff, 1998). In international arenas, human rights discourse and legislation provide ways to assert and argue for forms of justice that transcend local systems of honor, discrimination or political expediency (Donnelly, 2013). Human rights are framed in terms of common human needs for dignity, realization of capabilities, and flourishing but, again, the details of how this is to be achieved for people with specific social roles and positions may vary across societies (Appiah, 2011; Kateb, 2011; Kirmayer, 2012).

Existential meaning. Torture aims to isolate the individual from their usual frames of reference and make core values and commitments seem pointless or absurd. The loss of a stable community and cultural frame of reference can create a state of bewilderment and uncertainty, undermining the sense that one's life and actions have meaning and value. Commitment to the social cause or ideology of the threatened or oppressed group may mitigate the impacts of stress and torture (Barber et al., 2014; Başoğlu et al., 1997a,b; Willis, Chou \& Hunt, 2015). However, by insisting on the individual's powerlessness, torture may be deliberately organized to be maximally disruptive to the person's sense of agency, order, coherence and the possibility of meaningful action.

This list is not exhaustive but serves to enlarge our ways of thinking about the impact of torture and encourages us to look at the role of several different affective systems. Torture exerts its damaging effects through loss of sense of control, disruptions in interpersonal functioning, and the denigration and destruction of individual and group identity (Nickerson, Bryant, Rosebrook \& Litz, 2014). Intense emotions of fear, anger, shame, and disgust can all contribute to the suffering caused by torture. Undermining a sense of justice, meaning in life, and a valued social identity all serve 
to impair survivors' ability to exert control over their world. At the same time, others' awareness of the history of torture may have corrosive effects on the way they view the survivor and on the functioning of family and community. The broader meanings of torture can be elucidated by exploring the implications of the violence for the survivor, for their family, and for others in the community (Rousseau, 1995).

Torture survivors are often reluctant or unwilling to tell their stories of trauma before basic needs are met and trust is developed (Jaranson et al, 2001). They also may be unwilling to talk about their trauma experiences due to lack of confidence in health care staff, feelings of shame, fear of increasing their symptoms, or a lack of knowledge about available help (Jaranson, et al. 2001). Understanding the broad dimensions of experience that are attacked by torture and the intense emotions associated with these kinds of attacks on the person can guide practitioners in rebuilding survivors' sense of trust, self-efficacy, and control over their lives (Mollica, 2004; 2008).

\section{Emotions in cultural context}

Emotions reflect both putatively universal human systems of adaptation and culturespecific scripts rooted in particular forms of social life. There are universals of emotion rooted in biological, psychological, social and existential realities. At the biological level, for example, anger and fear reflect basic adaptive responses of fight or flight built into the nervous systems of animals that are predators and prey. Such basic emotions are shared with other animals and reflect biobehavioral patterns that organize motivated, adaptive behavior (Panksepp \& Biven, 2012). However, emotions also involve cognitive appraisal processes that determine what counts as danger, what future consequences are to be feared or expected, and how to respond behaviorally, beyond the initial physiological arousal. These attributions and interpretations reflect cognitive maps, models or schemas of situations. This process of appraisal and interpretation is crucial for more complex emotions, which reflect social scenarios and predicaments that follow particular cultural scripts (Oatley, Keltner, \& Jenkins, 2006). Such emotions can only be understood by appreciating the history, current context and future consequences embedded in that script. To the extent these scenarios describe a local social world or situation that depends on particular cultural institutions, identities, roles, and practices, the emotions they give rise to may be culturally distinctive.

As a result, emotions are grounded in meaning systems that shape the interpretation of experience. Because such interpretive systems depend on culture (Markus \& Kitayama, 1991), cognitive theories suggest that people learn to interpret their physiological signals, bodily sensations, and environmental contexts in different ways across cultures (Kitayama, Mesquita, \& Karasawa, 2001). Emotional response then is not directly determined by a situation or event but rather by the individual's appraisal of what the event means and by the responses of others. Thus, the learning theory of trauma, for example, builds on earlier work on stress and appraisal (Lazarus \& Folkman, 1984) to posit that individuals appraise potential threats to psychological well-being to determine whether such threats are controllable or not (Başoğlu, M., \& Salcioğlu, 2011; Başoğlu, 2017). Such appraisal influences subsequent emotional and behavioral responses.

How individuals appraise a particular situation depends on how they interpret 
its significance in terms of their personal history and cultural meaning systems. As a result, there may be significant differences in how people view even apparently similar events across cultures (Moors et al., 2013). Moreover, emotions differ across cultures to the extent that emotions reference particular kinds of social situations, scenarios or predicaments that depend on specific cultural notions of person, family and community (Lutz \& White, 1986). Culture-specific emotions may be built on the foundation of basic emotions but extend them through social scripts that give emotions new meaning, experiential contours and social consequences. In effect, emotions are embodied and embedded in specific social and cultural contexts that involve sequences of interpersonal actions and reactions (Boiger \& Mesquita, 2012). These interactions are part of social affordances that elicit and elaborate emotional responses (Ramstead, Veissière \& Kirmayer, 2016). Getting a clear picture of emotions requires thus learning more about their social contexts-including their developmental history, current configurations, and future consequenceswhich determine the experiential quality and temporal unfolding of the emotion (Prinz, 2014). These cultural dynamics of emotion will influence how the processes that mediate the suffering and sequelae of torture unfold over time in terms of emotional experience, symptoms, and functioning.

One way that appraisals vary crossculturally is connected with how people think about the relationship between self and others. For example, there is an extensive literature showing that certain cultures can be characterized as more relational or collectivistic, while others are more individualistic in orientation (Markus \& Kitayama, 1991). This is reflected in the ways that people respond to measures of basic emotions (Özkarar-Gradwohl et al., 2014). People from cultures that emphasize interdependence tend to think of themselves in relationship to others, while those from cultures that more highly value independence tend to think of themselves as interpersonally disengaged (Mesquita, \& Ellsworth, 2006). These preferred modes of self-construal influence the ways people respond to social situations, including those that involve moral transgressions (Dean \& Fles, 2015).

The ways in which societies exert social control may also be influenced by the perceived relationship between self and other. In cultural psychology and psychological anthropology, this has been framed in terms of cultural differences in the relative emphasis on shame or guilt for social control (Wong \& Tsai, 2007). In more relational cultures, a primary device for maintaining social order may be the inculcation of shame, with the concomitant threat of social exclusion. In more individualistic cultures, social control may be maintained more often by creating and reinforcing feelings of guilt for engaging in prohibited behaviors. Whereas shame is experienced in response to perceived moral violations in the eyes of the other, guilt is experienced when individuals violate their own internalized moral standards. It is important to note, however, that this contrast is framed from an individualistic perspective that downplays the extent to which all self-experience, evaluation and direction are grounded in social models, norms, and the expectations of others. To the extent that individuals' sense of self incorporates the gaze of the other, the distinction between shame and guilt breaks down and more complex accounts are needed to capture multiple facets of the self 
and their influence on cultural variations in emotion (Kirmayer 2007b).

Björkqvist (2017) discusses how shame serves social regulatory functions and how social shaming and exclusion can cause intense pain, which may be mediated by attachment systems. The self-conscious emotions of shame and guilt have been termed "moral emotions" because they are linked to perceived violations of a moral code (Morgan, 2011; Williams, 2008). In a sense, though, any emotion linked to particular social events and outcomes may function as a moral emotion (Frijda, 2004). Moral emotions locate socially valued (or prohibited) behaviors within a larger cultural matrix of desirable and appropriate (or harmful and transgressive) values, goals and behaviors. Research by Shweder and colleagues (2003) emphasizes that people in different parts of the world tend to use different kinds of moral codes to guide their moral judgements and distinguish three kinds of moral codes or "ethics": 1) Ethics of autonomy, in which morality is viewed in terms of individual freedoms and rights violations; 2) Ethics of community, where morality is conceived in terms of the duties individuals have to perform in accordance with their role in the community; and 3) Ethics of divinity, in which morality revolves around concerns about purity or sanctity and the perceived "natural order" of things. Rozin and colleagues (1999) found that violation of each of these codes produced specific moral emotions: Violations of the ethic of autonomy tend to provoke anger; when the ethic of community is violated it leads to contempt toward to the violator; and violations of the ethic of divinity evoke disgust. When the violator is victim, made to violate as part of the regime of torture, the negative emotions may be self-directed. These codes are not arbitrary or abstract systems but are based on cultural systems of meaning and grounded in social practices. The experience of specific moral emotions gives cultural systems of meaning and value their cogency and bodily-felt immediacy.

\section{Moral emotions and the logic of torture}

These considerations on cultural variations in emotion have implications for how we think about torture. Moral emotions play a central role in the logic of torture. The ethical or moral codes that are transgressed in specific acts of torture may give rise to particular emotions. In general, any context of torture will involve transgression of multiple codes. For example, rape may be seen as a violation of personal autonomy, social bonds and identity, and purity. This would be expected to differentially elicit feelings of anger, shame, and disgust, respectively. In most instances, all of these emotions will be evoked but with varying intensities and implications that depend on cultural meaning and explanations.

Through knowledge of what constitutes a moral violation or transgression, the torturer seeks to cause maximal suffering, loss of control, shame and humiliation to destroy the dignity of the individual and nullify their social standing, sense of self-efficacy and selfrespect. The particular ways that torturers do this draw from psychological universals but also employ knowledge of cultural systems of meaning and social contexts, especially those situations that tap into moral emotions. Başoğlu (2017) cites evidence suggesting that the traumatic impact of humiliating treatments or attacks on personal integrity, cultural values, morals, or religious beliefs is mediated in part by helplessness arising from inability to act on anger and hostility generated by such aversive treatment. Guilt, shame and humiliation may have other 
corrosive effects related to the individual's loss of valued social identity and position. Identifying the pathways by which torture exerts its immediate and long-term effects therefore requires knowledge of the cultural meanings of the torture in relation to the communities from which survivors come and those to which they return.

Any noxious sensation or emotion that is sufficiently intense and uncontrollable can lead to profound feelings of demoralization and powerlessness. Intense feelings of anger, shame, and disgust all can play a role in causing emotional injury. For example, intense shame can disorganize thinking and impair coping and interpersonal interactions; intense anger can be equally disorganizing. These noxious emotions can also be conditioned to trauma-related cues and persist or recur despite individuals' efforts at mastery and recovery. Because such conditioned emotional responses can be intense, derailing, and difficult to suppress, emotions like fear, shame, disgust not only may be inherently distressing in terms of their experiential quality (Levinas, 2003) but also signal loss of control through cognitive, emotional and bodily responses (e.g. trembling, urination; fainting; retching) in ways that add to the person's experience of shame and helplessness.

Beyond causing immediate distress, the experience of intense negative emotions can reorganize behavior through processes of memory, conditioned learning and coping responses in ways that leads to continued suffering and disability. Emotions like shame serve to organize salient memories, and rumination on shameful experiences can be intensely preoccupying, impairing social functioning and contributing to anxiety and depression (Matos, Pino-Gouvela \& Duarte, 2012). In addition to these cognitive influences on memory, conditioned emotional responses can exert profound effects on aspects of bodily and psychological functioning in ways that occur outside of an individual's conscious cognition. Thus, just as cues associated with pain can evoke fear in anticipation of future pain, so too can cues associated with nausea come to evoke feelings of queasiness and disgust. In fact, we are biologically prepared to learn to associate nausea and disgust with salient stimuli. The capacity for disgust is hardwired and likely served evolutionary functions of avoiding potentially toxic, infectious or parasitic disease (Curtis, 2013). Thus, responses of disgust in response to bodily transgression can occur rapidly, without much cognitive mediation, and be extremely difficult to suppress (Russell \& Giner-Sorolla, 2013). But this basic bodily response can be readily linked to other symbolic stimuli. What counts as disgusting, then, reflects a personal and cultural history of exposures. Thus, a person who observes Muslim dietary rules of halal might develop intense feelings of nausea and disgust when forced to eat pork. Moreover, in every culture disgust is elaborated and becomes linked to more complex social cues associated with symbolic notions of impurity and moral transgression. Symbolic acts that violate cultural norms of purity can then be used to evoke intense disgust and even nausea, which-when sufficiently intense, uncontrollable and persistent - may lead to enduring feelings of helplessness. Koenig (2017) provides clear examples of how violation of cultural norms was used to induce shame and helplessness in Guantanamo detainees. Deliberate transgression of religious symbols of the sacred has been used to deliver faith-based torture (Khan, 2010).

Shame and humiliation play major roles in most forms of torture. Budden (2009) has argued that shame is an important mediator of the effects of trauma both in the acute stage 
and in later coping. Moreover, shame is central to the social consequences of trauma. Two broad sources of shame can be distinguished:

1) failure to conform to social norms and expectations; and 2) loss of social status or experience of one's inferior status (Fessler, 1999, 2007). These forms of shame may serve to maintain social order through conformity and hierarchy, respectively, and may be closely coupled, when failure to perform according to norms leads to loss of social status or when diminished social status impedes the individual's capacity to maintain appropriate behavior. However, cultures vary in the extent to which they distinguish between the two forms. To take the examples offered by Fessler (2004), in North American English, the word "shame" tends to be applied mainly to feelings in situations of failure to conform to social norms and expectations. In Bengali and some other Indian languages, lajja refers primarily to a sense of shame associated with status inferiority (Sinha \& Chouhan, 2013). In Indonesia, malu refers to both status inferiority and failure to conform (Röttger-Rössler et al., 2013). This conjunction may reflect the fact that maintaining the status hierarchy is a key social norm and that reminders of one's lower status serve a social regulatory function.

In torture, intense feelings of status inferiority are created by acts of domination that cause acute subjugation. This results in a loss of agency and control, which when persistent and profound leads to feelings of helplessness. In ordinary social life, we exert control not only through our own actions but by eliciting cooperative responses from others. The whole context of torture violates social norms and expectations for recognition, cooperation, care, reciprocity and respect from others. Victims experience powerlessness not only because of their personal loss of control over circumstances and behavior but also because of the abrogation of basic social expectations for predictable responses and cooperation from others. Moreover, in torture individuals may lose control over both bodily functions and the social presentation of self as a consequence of violence and deprivation or may be forced to explicitly violate social norms by their own actions under coercion leading to a loss of moral integrity and rupture of social identity. While these forms of violence rely on universal logics of emotion and psychophysiological mechanisms that make them just as intense as processes that involve physical pain or terror, their initial impact and long term consequences also depend on specific cultural frameworks that confer meaning and provide modes of explanation.

People have implicit causal theories they invoke to explain both actions and afflictions. These theories draw from cultural systems of practical and moral reasoning (Tilly, 2006). The psychological and social consequences of specific explanations depend on larger systems of meaning that are embedded in particular ways of life and that reference cultural ontologies that identify what kinds of entities or processes can act as causal agent. Explanations of complex events often use concepts drawn from multiple frameworks and a range of ontologies can be invoked in response to torture based on the context in which it occurs. In the case of torture in the context of war, socio-political explanations may be relevant. Understanding torture as a risk related to one's political commitments may help individuals to prepare to endure it, confer a level of control over the experience since it is framed as a consequence of political choices or resistance, and help to make sense of suffering (Başoğlu et al., 1997a,b; Punamäki et al., 2008). However, given that torture often involves the transgression of moral codes, moral explanations are 
commonly used. In addition to anger directed toward the torturer, survivors of torture may perceive themselves as having transgressed moral boundaries. In part, this may reflect a general tendency to understand misfortune in terms of one's own actions or to consider that one might have done something to avoid adverse outcomes. This attribution may serve to maintain an illusion of control in situations of helplessness or reframe the torture in ways that maintain a sense of moral order. However, in many instances, the torturer aims to make the survivor feel responsible for all that has befallen him or her as part of the attack on social personhood or on the larger community. This may include blaming the victim bringing suffering and loss to their own loved ones. To the extent that this attribution succeeds, victims may see themselves as the architects of their own suffering. Finally, the arbitrariness and lack of correlation or proportion between action and response in the delivery of violence that is part of the deliberate design of torture may have a corrosive effect on the survivor's sense of justice and coherence.

\section{Learned helplessness and loss of control}

Torture renders the individual helpless and defenseless both physically and psychologically. Indeed, the structure of torture, with repeated experiences of loss of control, works to dismantle the individual's sense of self-efficacy and moral worth in ways that may persist after their release and engagement with new social situations. The experience of being forcibly confined and cut-off from ordinary social interaction, relationships and supports destabilizes the person's sense of identity and control (Gallagher, 2014), which are ordinarily maintained by cooperative and reciprocal relationships with others. Normal strategies to deflect, reject and resist abuse are no longer possible. This confinement, domination and violence force the person to endure unbearable suffering, to comply with his tormentor and to agree to actions utterly inconsistent with his values and identity. This coercion aims to destroy personal integrity. Breaking down individuals' resistance and forcing them to perform transgressive acts "voluntarily" leads to a loss of agency and dignity. The shame and humiliation that follow from such subjugation contribute to feelings of utter helplessness that come from being forced into passivity and "acted upon" as a dehumanized object.

Many of the effects of torture, including the impact of shame and humiliation, can been understood in terms of the theory of learned helplessness (Abramson, Seligman, \& Teasdale, 1978; Başoğlu, 1992; Başoğlu \& Salcioğlu, 2011). Aspects of everyday life that are commonly understood as being normally or potentially under the individual's personal control include bodily functions, choices of action, and self-presentation. Torture works to undermine these domains of control and self-mastery, not only in the moment but into the future. It accomplishes this by repetitive attacks, coercion, pervasive uncertainty, and direct undermining of efforts to re-establish control.

The domains where individuals expect controllability also depend on cultural ontologies and explanations. Not every kind of event is viewed as (potentially) controllable. Explaining events in terms of forces or agencies like fate or "God's will" that lie beyond anyone's control may help some individuals to endure but they may also lead to ineffective coping strategies that impair functioning. On the other hand, traditions that emphasize coping by controlling one's own mind may help individuals endure experiences of loss of behavioral control and the same attitudes 
may help with subsequent adaptation (Agger, 2015; Elsass, Carlsson, Jesperson, \& Phuntsok, 2008; Elssass \& Phuntsok, 2009; Kohrt \& Hruschka, 2010). Forcing individuals to transgress cultural and religious norms and values then constitutes multiple forms of violence, causing direct injury, blocking efforts to give meaning to suffering, and damaging their social identity in ways that may lead to persistent feelings of estrangement from others (Khan, 2010; Kirmayer, 2015).

\section{Conclusion}

Torture involves many forms of violence, targeting multiple systems involved in the response to intense fear, physical and emotional pain, threat or injury to loved ones, loss of social bonds, hopelessness, helplessness, and humiliation. The impact of torture involves not only its physical and psychological effects on the sufferer but its social meaning to all involved. These meanings are interpreted and understood through systems of cultural knowledge and practice, which contribute to the social and psychological dynamics of emotion.

To more fully grasp patients' experience, clinicians need to map the social spaces, body practices, scripts, and contexts that give moral emotions their meaning and consequences. This map includes the tacit dimensions of experience which individuals may not be able to describe but only show. Important aspects of cultural meaning may remain unsaid because of suppression, avoidance, or dissociation or unsayable because they are hypocognized and embedded in external affordances. Eliciting this information may require discussion with others as well as family, home, or community visits. This mapping can include: the pretorture context, where it can elucidate structures of meaning that are associated with vulnerability and resilience; the context of torture, where it can help explain the impact of specific forms of violence; and current contexts of adaptation, where it shapes the dynamics of hope and recovery.

Discussions of culture in mental health often focus on traits or characteristics of designated others (usually 'non-Western' peoples) who are depicted as different in relation to the tacit or explicit norms of Western societies. Becoming aware of and "sensitive" to these differences is supposed to improve care (Kirmayer et al., 2016). However, in practice, this sometimes results in crude stereotypes that may impede clinical understanding and rapport. Moreover, this approach hides what is most central to culture, namely the taken-for-granted assumptions of the observer. From this perspective, the cultures that are most important in clinical practice include those of the receiving society, the practitioner, and of the profession itself, which provide the background knowledge and implicit norms that are used to judge what is unusual, interesting, or clinically relevant about others.

Lack of understanding of others' cultural worlds leads to inhumane responses to their predicaments. This failure of empathy and imagination is seen both in public policy and in the microcosm of clinical care. In recent years, many countries have begun to renege on their commitments to receiving refugees, and those who make it to the shores of a safe country may face systemic discrimination, as well as skepticism and disbelief when they recount their experiences (Kirmayer, 2007a). Mapping the social and emotional meanings and consequences of torture can foster better understanding and more appropriate social, political and clinical responses.

Taking local meanings of emotion seriously has implications for how we measure 
outcomes in research, clinical assessments, or human rights advocacy. We need to look not only at physical and psychological symptoms but also to broader adaptive functioning in terms of individuals' ability to feel confidence in their own capacities, in the predictability of the world, and the trustworthiness of the human community (Campbell, 2007; Jaranson \& Popkin, 1998; Kirmayer, Rousseau \& Measham, 2010). Torture has consequences not just for individuals' physical health, cognitive-emotional functioning, and psychological well-being but also for their relationships with others (Maercker \& Horn, 2013; Nickerson et al., 2014). Of course, the quality of interpersonal relationships and social interactions is closely related to individual's psychological functioning. Hence, when psychological treatment improves individual functioning, relationships with others may also improve. But the causal process works the other way as well: forms of political violence directed to families and communities that disrupt trust and social bonds, increase the risk of trauma-related disorders among everyone and may be stronger predictors of PTSD among torture survivors than the torture experience itself (Başoğlu et al., 2005). This has wider ramifications for families and communities. Beyond individual impacts, then, we need to consider the ways in which the impact of torture disrupts families and communities and contributes over to time to cycles of violence. Understanding the cultural contexts of torture and its aftermath is essential both for effective treatment of survivors and for the prevention of torture.

\section{Acknowledgements}

We thank Metin Başoğlu and two anonymous reviewers for helpful comments on earlier versions of this paper and Elizabeth Anthony for editorial advice.

\section{References}

Abramson, L.Y., Seligman, M. E. P., \& Teasdale, J. D. (1978). Learned helplessness in humans: Critique and reformulation. Fournal of Abnormal Psychology, 87, 49-74. http:// doi.org/10.1037/0021843X.87.1.49

Agger, I. (2015). Calming the mind: Healing after mass atrocity in Cambodia. Transcultural Psychiatry, 52(4), 543-560. http://doi. org/10.1177/1363461514568336

American Psychiatric Association. (2013). Diagnostic and Statistical Manual of Mental Disorders (DSM5). Washington: American Psychiatric Pub.

Appiah, K. A. (2011). The honor code: How moral revolutions happen. New York: WW Norton \& Co.

Avruch, K. (2010). Truth and reconciliation commissions: problems in transitional justice and the reconstruction of identity. Transcultural Psychiatry, 47(1), 33-49. http://doi. org/10.1177/1363461510362043

Barber, B. K., Spellings, C., McNeely, C., Page, P. D., Giacaman, R., Arafat, C., . . Abu Mallouh, M. (2014). Politics drives human functioning, dignity, and quality of life. Social Science $\mathcal{E}$ Medicine, 122, 90-102. http://doi.org/10.1159/000369328

Başoğlu, M. (Ed.). (1992). Torture and its consequences: Current treatment approaches. Cambridge, UK: Cambridge University Press.

Başoğlu, M. (Ed.). (2017). Torture and its definition in international law: An interdisciplinary approach. New York: Oxford University Press. http://doi. org/10.1093/med/9780199374625.001.0001

Başoğlu, M., Livanou, M., Crnobarić, C., Frančišković, T., Suljić, E., Đurić, D., \& Vranešić, M. (2005). Psychiatric and cognitive effects of war in former Yugoslavia: association of lack of redress for trauma and posttraumatic stress reactions. Fournal of the American Medical Association, 294(5), 580-590. http://doi.org/10.1001/ jama.294.5.580

Başoğlu, M., Mineka, S., Paker, M., Aker, T., Livanou, M., \& Gok, S. (1997a). Psychological preparedness for trauma as a protective factor in survivors of torture. Psychological Medicine, 27(6), 1421-1433.

Başoğlu, M., Paker, M., Paker, O., Ozmen, E., Marks, I., Incesu, C., . . . Sarimurat, N. (1997b). Psychological effects of torture: a comparison of tortured with nontortured political activists in Turkey. American fournal of Psychiatry, 151(1), 76-81. http://doi.org/10.1176/ajp.151.1.76

Başoğlu, M., \& Salcioğlu, E. (2011). A Mental Healthcare Model for Mass Trauma Survivors: ControlFocused Behavioral Treatment of Earthquake, War and Torture Trauma. Cambridge, UK: Cambridge University Press. 
Batson, C. D., Chao, M. C., \& Givens, J. M. (2009). Pursuing moral outrage: Anger at torture. fournal of Experimental Social Psychology, 45, 155-160. http://doi.org/10.1016/j.jesp.2008.07.017

Björkqvist, K. (2017). An evolutionary approach to humiliation and shame induced by inhuman and degrading treatment. In: Başoğlu, M. (Ed.). Torture and its definition in international law: $A n$ interdisciplinary approach (pp. 91-106). New York: Oxford University Press.

Boiger, M., \& Mesquita, B. (2012). The construction of emotion in interactions, relationships, and cultures. Emotion Review, 4(3), 221-229. https://doi. org/10.1177/1754073912439765

Bolton, P., Surkan, P. J., Gray, A. E., \& Desmousseaux, M. (2012). The mental health and psychosocial effects of organized violence: A qualitative study in northern Haiti. Transcultural Psychiatry, 49(3-4), 590-612. https://doi. org/10.1177/1363461511433945

Brewin, C. R., Andrews, B., \& Valentine, J. D. (2000). Meta-analysis of risk factors for posttraumatic stress disorder in trauma-exposed adults. Fournal of Consulting and Clinical Psychology, 68(5), 748. http://doi.org/10.1037/0022-006X.68.5.748

Breyer, T. (2017). Violence as violation of experiential structures. Phenomenology and the Cognitive Sciences, 16(4), 737-751. https://doi.org/10.1007/ s11097-016-9476-9

Budden, A. (2009). The role of shame in posttraumatic stress disorder: a proposal for a socio-emotional model for DSM-V. Social Science and Medicine, 69(7), 1032-1039. https://doi.org/10.1016/j. socscimed.2009.07.032

Campbell, T. A. (2007). Psychological assessment, diagnosis, and treatment of torture survivors: a review. Clinical Psychology Review, 27(5), 628-641. http://doi.org/10.1016/j.cpr.2007.02.003

Curtis, V. (2013). Don't look, don't touch, don't eat: the science behind revulsion. Chicago: The University of Chicago Press.

Dean, K. K., \& Fles, E. H. (2015). The effects of independent and interdependent selfconstruals on reactions to transgressions: distinguishing between guilt and shame. Self and Identity, 1-17.

Donnelly, J. (2013). Universal human rights in theory and practice. Ithaca, NY: Cornell University Press.

Eisenberger, N. I. (2015). Social pain and the brain: controversies, questions, and where to go from here. Annual Review of Psychology, 66, 601-629. http://doi.org/10.1146/annurevpsych-010213-115146

Ekblad, S., \& Jaranson, J. (2004). Psychosocial rehabilitation. In Wilson J, \& Drozdek B., (eds.) Broken spirits: the treatment of traumatized asylum seekers, refugees, war and torture victims. New York: Brunner-Routledge Press, pp. 609-36. http://doi. org/10.1176/appi.ajp.162.9.1768

Elsass, P., Carlsson, J., Jespersen, K., \& Phuntsok, K. (2008). Questioning western assessment of trauma among Tibetan torture survivors. A quantitative assessment study with comments from Buddhist Lamas. Torture, 19(3), 194-203.

Elsass, P., \& Phuntsok, K. (2009). Tibetans' coping mechanisms following torture: an interview study of Tibetan torture survivors' use of coping mechanisms and how these were supported by western counseling. Traumatology, 15(1), 3-10. http://doi. org/10.1177/1534765608325120

Fessler, D. M. T. (1999). Toward an understanding of the universality of second order emotions. In A. L. Hinton (Ed.), Biocultural approaches to the emotions (pp. 75-116). New York: Cambridge University Press.

Fessler, D. M. T. (2004). Shame in two cultures: Implications for evolutionary approaches. Fournal of Cognition and Culture, 4(2), 207-262. http://doi. org/10.1163/1568537041725097

Fessler, D. M. T. (2007). From appeasement to conformity: evolutionary and cultural perspectives on shame, competition, and cooperation. In J. L. Tracy, R. W. Robbins, \& J. P. Tangney (Eds.), The self-conscious emotions: Theory and research (pp. 174-193). New York: Guilford Press.

Fiske, A. P., \& Rai, T. S. (2015). Virtuous violence: Hurting and killing to create, sustain, end and honor social relationships. New York: Cambridge University Press. https://doi.org/10.1017/ CBO9781316104668

Frijda, N. H. (2004). Emotions and action. In: Manstead, A. S., Frijda, N., \& Fischer, A. (Eds.). Feelings and emotions: The Amsterdam symposium (pp. 158-173). Cambridge, UK: Cambridge University Press. http://doi.org/10.1017/ CBO9780511806582.010

Gallagher, S. (2014). The cruel and unusual phenomenology of solitary confinement. Frontiers in Psychology, 5. http://doi.org/10.3389/fpsyg.2014.00585

Hatfield, E., \& Rapson, R. L. (2005). Social justice and the clash of cultures. Psychological Inquiry, 16(4), 172-175. http://doi.org/10.1207/ s15327965pli1604_06

Hinton, D. E., \& Lewis-Fernández, R. (2011). The cross-cultural validity of posttraumatic stress disorder: implications for DSM-5. Depression and Anxiety, 28(9), 783-801. http://doi.org/10.1002/ da. 20753

Ignatieff, M. (1998). The warrior's honor: ethnic war and the modern conscience. New York: Metropolitan Books. 
Jaranson, J. M., Kinzie, J. D., Friedman, M., Ortiz, S. D., Friedman, M. J., Southwick, S., ... \& Mollica, R. (2001). Assessment, diagnosis, and intervention. In Gerrity, E., Keane, T. M., \& Tuma, F. (Eds.). The mental health consequences of torture (pp. 249-275). Springer, Boston, MA. http:// doi.org/10.1007/978-1-4615-1295-0_16

Jaranson, J., \& Popkin, M. (Eds.). (1998). Caring for Victims of Torture. Washington, DC: American Psychiatric Press.

Johansen, V. A., Wahl, A. K., Eilertsen, D. E., \& Weisaeth, L. (2007). Prevalence and predictors of post-traumatic stress disorder (PTSD) in physically injured victims of non-domestic violence. Social Psychiatry and Psychiatric Epidemiology, 42(7), 583593. http://doi.org/10.1007/s00127-007-0205-0

Johnson, H., \& Thompson, A. (2008). The development and maintenance of post-traumatic stress disorder (PTSD) in civilian adult survivors of war trauma and torture: a review. Clinical Psychology Review, 28(1), 36-47. http://doi.org/10.1016/j. cpr.2007.01.017

Kagee, A., \& Naidoo, A. V. (2004). Reconceptualizing the sequelae of political torture: limitations of a psychiatric paradigm. Transcultural Psychiatry, 41(1), 46-61. https://doi. org/10.1177/1363461504041353

Kateb, G. (2011). Human dignity. Cambridge, MA: Harvard University Press.

Khan, A. (2010). Faith-based torture. Global Dialogue, 12(1-2), 1-10.

Kirmayer, L. J. (2007a). Failures of imagination: The refugee's predicament. In L. J. Kirmayer, R. Lemelson \& M. Barad (Eds.), Understanding Trauma: Biological, Psychological and Cultural Perspectives (pp. 363-381). New York: Cambridge University Press. http://doi. org/10.1080/1364847032000122843

Kirmayer, L. J. (2007b). Psychotherapy and the cultural concept of the person. Transcultural Psychiatry, 44(2), 232-257. http://doi. org/10.1177/1363461506070794

Kirmayer, L.J. (2008). Culture and the metaphoric mediation of pain. Transcultural Psychiatry, 45(2): 318-338. http://doi. org/10.1177/1363461508089769

Kirmayer, L. J. (2012). Culture and context in human rights. In M. Dudley, D. Silove \& F. Gale (Eds.), Mental Health and Human Rights:Vision, Praxis and Courage (pp. 95-112). Oxford: Oxford University Press.

Kirmayer, L. J. (2015). Wrestling with the angels of history: Memory, symptom, intervention. In A. L. Hinton \& D. Hinton (Eds.), Genocide and Mass Violence: Memory, Symptom, and Recovery (pp. 388-420). Cambridge, UK: Cam- bridge University Press. http://doi.org/10.1017/ CBO9781107706859.023

Kirmayer, L. J., Bennegadi, R., \& Kastrup, M. C. (2016). Cultural awareness and responsiveness in person-centered psychiatry. In J. Mezzich et al. (Eds.) Person Centered Psychiatry (pp. 77-95). New York: Springer. http://doi.org/10.1007/9781-4615-1295-0_16

Kirmayer, L. J., Kienzler, H., Afana, A. H., \& Pedersen, D. (2010). Trauma and disasters in social and cultural context. In D. Bhugra \& C. Morgan (Eds.), Principles of Social Psychiatry (2 ed., pp. 155-177). New York: Wiley-Blackwell.

Kirmayer, L.J., Lemelson, R. \& Barad, M. (2007). Inscribing trauma in culture, brain and body. In: Kirmayer, L.J., Lemelson, R. \& Barad, M. (Eds.) Understanding Trauma: Integrating Biological, Clinical and Cultural Perspectives, (pp. 1-27). New York: Cambridge University Press. http://dx.doi. org/10.1017/CBO9780511500008

Kirmayer, L. J., \& Ramstead, M. J. (2017). Embodiment and enactment in cultural psychiatry. In: C. Durt, T. Fuchs, \& C. Tewes (Eds.) Embodiment, Enaction, and Culture: Investigating the Constitution of the Shared World (pp. 397-422). Cambridge, MA: MIT Press.

Kirmayer, L. J., Rousseau, C., \& Measham, T. (2010). Sociocultural considerations. In D. Benedek \& G. H. Wynn (Eds.), Clinical Manual for the Management of Posttraumatic Stress Disorder. Washington: American Psychiatric Publishing, Inc.

Kitayama, S., Mesquita, B., \& Karasawa, M. (2006). Cultural affordances and emotional experience: socially engaging and disengaging emotions in Japan and the United States. Fournal of Personality and Social Psychology, 91(5), 890. http://dx.doi. org/10.1037/0022-3514.91.5.890

Koenig, K.A. (2017). A battle for control: Resisting torture, and cruel, inhuman or degrading treatment at Guantánamo. In: Başoğlu, M. (Ed.). (2017). Torture and its definition in international law: An interdisciplinary approach (pp. 61-90). New York: Oxford University Press.

Kohrt, B. A., \& Hruschka, D. J. (2010). Nepali concepts of psychological trauma: the role of idioms of distress, ethnopsychology and ethnophysiology in alleviating suffering and preventing stigma. Culture, Medicine, and Psychiatry, 34(2), 322-352. https://doi.org/10.1007/s11013-010-9170-2

Lazarus, R. S., \& Folkman, S. (1984). Stress, coping and appraisal. New York: Springer.

Lee, D. A., Scragg, P., \& Turner, S. (2001). The role of shame and guilt in traumatic events: A clinical model of shame-based and guilt-based PTSD. British fournal of Medical Psychology, 74(4), 451466. doi:10.1348/000711201161109 
Levenson, R. W. (2014). The autonomic nervous system and emotion. Emotion Review, 6(2), 100-112. https://doi.org/10.1177/1754073913512003

Levinas, E. (2003). On Escape. Stanford: Stanford University Press.

Lutz, C., \& White, G. M. (1986). The anthropology of emotions. Annual Review of Anthropology, 15(1), 405-436. http://dx.doi.org/10.1146/ annurev.an.15.100186.002201

Maercker, A., \& Horn, A. B. (2013). A socio-interpersonal perspective on PTSD: the case for environments and interpersonal processes. Clinical Psychology \& Psychotherapy, 20(6), 465-481. DOI:10.1002/cpp.1805

Markus, H. R., \& Kitayama, S. (1991). Culture and the self: Implications for cognition, emotion, and motivation. Psychological Review, 98(2), 224. DOI:10.1037//0033-295X.98.2.224

Matos, M., Pinto-Gouveia, J., \& Duarte, C. (2012). Above and beyond emotional valence: The unique contribution of central and traumatic shame memories to psychopathology vulnerability. Memory, 20(5), 461-477. https://doi.org/10.10 80/09658211.2012.680962

McGregor, L. S., Melvin, G. A., \& Newman, L. K. (2016). An exploration of the adaptation and development after persecution and trauma (ADAPT) model with resettled refugee adolescents in Australia: A qualitative study. Transcultural Psychiatry, 53(3), 347-367. https://doi. org/10.1177/1363461516649546

Mendeloff, D. (2009). Trauma and vengeance: Assessing the psychological and emotional effects of post-conflict justice. Human Rights Quarterly, 31(3), 592-623. DOI:10.1353/hrq.0.0100

Mesquita, B. \& Ellsworth, P. C. (2001). The role of culture in appraisal. In: Scherer, K. R., Schorr, A. \& Johnstone, T. (Eds). Appraisal processes in emotion: Theory, methods, research (pp. 233-248). New York, NY, US: Oxford University Press.

Miller, K. E., \& Rasmussen, A. (2010). War exposure, daily stressors, and mental health in conflict and post-conflict settings: bridging the divide between trauma-focused and psychosocial frameworks. Social Science \& Medicine, 70(1), 7-16. https://doi.org/10.1016/j. socscimed.2009.09.029

Mollica, R. F. (2004). Surviving torture. New England Fournal of Medicine, 351(1), 5-7. DOI:10.1056/ NEJMp048141

Mollica, R. F. (2008). Healing invisible wounds: Paths to hope and recovery in a violent world. Vanderbilt University Press.

Moors, A., Ellsworth, P. C., Scherer, K. R., \& Frijda, N. H. (2013). Appraisal theories of emotion: State of the art and future development.
Emotion Review, 5(2), 119-124. https://doi. org/10.1177/1754073912468165

Morgan, M. (2011). On shame. New York: Routledge.

Nickerson, A., Bryant, R. A., Rosebrock, L., \& Litz, B. T. (2014). The mechanisms of psychosocial injury following human rights violations, mass trauma, and torture. Clinical Psychology: Science and Practice, 21(2), 172-191. DOI: 10.1111/cpsp.12064

Oatley, K., Keltner, D., \& Jenkins, J. M. (2006). Understanding emotions. Oxford: Blackwell Publishing.

Ozer, E. J., Best, S. R., Lipsey, T. L., \& Weiss, D. S. (2003). Predictors of posttraumatic stress disorder and symptoms in adults: a meta-analysis. Psychological Bulletin, 129(1), 52-73. DOI:10.1037/0033-2909.129.1.52

Özkarar-Gradwohl, F. G., Panksepp, J., İçöz, F. J., Çetinkaya, H., Köksal, F., Davis, K. L., \& Scherler, N. (2014). The influence of culture on basic affective systems: the comparison of Turkish and American norms on the affective neuroscience personality scales. Culture and Brain, 2(2), 173-192. https://doi.org/10.1007/ s40167-014-0021-9

Panksepp, J., \& Biven, L. (2012). The archaeology of mind: neuroevolutionary origins of human emotions. New York: WW Norton \& Company.

Perez-Sales, P. (2016). Psychological torture: Definition, evaluation and measurement. New York: Routledge.

Porter, M., \& Haslam, N. (2005). Predisplacement and postdisplacement factors associated with mental health of refugees and internally displaced persons: a meta-analysis. Fournal of the American Medical Association, 294(5), 602-612. DOI: 10.1001/jama.294.5.602

Prinz, J. J. (2014). Where do morals come from?-A plea for a cultural approach. In Empirically Informed Ethics: Morality between Facts and Norms (pp. 99-116). New York: Springer.

Punamäki, R. L., Salo, J., Komproe, I., Qouta, S., El-Masri, M., \& De Jong, J. T. (2008). Dispositional and situational coping and mental health among Palestinian political ex-prisoners. Anxiety, Stress, \& Coping, 21(4), 337-358. https:/doi. org/10.1080/10615800701797333

Ramstead, M. J., Veissière, S. P., \& Kirmayer, L. J. (2016). Cultural affordances: scaffolding local worlds through shared intentionality and regimes of attention. Frontiers in Psychology, 7. doi: 10.3389/fpsyg. 2016.01090

Röttger-Rössler, B., Scheidecker, G., Jung, S., \& Holodynski, M. (2013). Socializing emotions in childhood: A cross-cultural comparison between the Bara in Madagascar and the Minangkabau in Indonesia. Mind, Culture, and Activity, 20(3), 260-287. https://doi.org/10.1080/10749039.20 13.806551 
Rousseau, C. (1995). The "significance" of torture experiences: Towards an awareness of individual, family and cultural factors Community Support for Survivors of Torture: A Manual (pp. 29-35). Toronto: Canadian Center for Victims of Torture.

Rozin, P., Lowery, L., Imada, S., \& Haidt, J. (1999). The CAD triad hypothesis: a mapping between three moral emotions (contempt, anger, disgust) and three moral codes (community, autonomy, divinity). Fournal of Personality and Social Psychology, 76(4), 574. http://dx.doi. org/10.1037/0022-3514.76.4.574

Russell, P. S., \& Giner-Sorolla, R. (2013). Bodily moral disgust: What it is, how it is different from anger, and why it is an unreasoned emotion. Psychological Bulletin, 139(2), 328. DOI:10.1037/a0029319

Shalev, A.Y. (2007). PTSD: a disorder of recovery? In L. J. Kirmayer, R. Lemelson, \& M. Barad (Eds.), Understanding trauma: Integrating biological, clinical, and cultural perspectives (pp. 207-223) New York: Cambridge University Press. http:// doi.org/10.1080/1364847032000122843

Shweder, R. A., Much, N. C., Mahapatra, M., \& Park, L. (2003). The "big three" of morality (autonomy, community, divinity) and the big three explanations of suffering. In: R. Shweder, Why Do Men Barbecue? Recipes for Cultural Psychology. Cambridge, MA: Harvard University Press.

Silove, D. (1999). The psychosocial effects of torture, mass human rights violations, and refugee trauma: toward an integrated conceptual framework. Fournal of Nervous \& Mental Disease, 187(4), 200-207. DOI:10.1097/00005053-199904000-00002

Silove, D. (2007). Adaptation, ecosocial safety signals, and the trajectory of PTSD. In L. J. Kirmayer, R. Lemelson \& M. Barad (Eds.), Understanding Trauma: Integrating Biological, Psychological and Cultural Perspectives (pp. 242-258). New York: Cambridge University Press. http://doi. org/10.1080/1364847032000122843

Silove, D., Austin, P., \& Steel, Z. (2007). No refuge from terror: the impact of detention on the mental health of trauma-affected refugees seeking asylum in Australia. Transcultural Psychiatry, 44(3), 359393. https://doi.org/10.1177/1363461507081637

Sinha, M., \& Chauhan, V. (2013). Deconstructing lajiA as a marker of Indian womanhood. Psychology \& Developing Societies, 25(1), 133-163. https://doi.org/10.1177/0971333613477314

Somasundaram, D. (2008). Psychosocial aspects of torture in Sri Lanka. International fournal of Culture and Mental Health, 1(1), 10-23. https:/doi. org/10.1080/17542860802102158

Steel, Z., Chey, T., Silove, D., Marnane, C., Bryant, R. A., \& van Ommeren, M. (2009). Association of torture and other potentially traumatic events with mental health outcomes among populations exposed to mass conflict and displacement: a systematic review and meta-analysis. Fournal of the American Medical Association, 302(5), 537-549. DOI:10.1001/jama.2009.1132

Tay, A. K., Rees, S., Chan, J., Kareth, M., \& Silove, D. (2015). Examining the broader psychosocial effects of mass conflict on PTSD symptoms and functional impairment amongst West Papuan refugees resettled in Papua New Guinea (PNG). Social Science and Medicine, 132, 70-78. https:// doi.org/10.1016/j.socscimed.2015.03.020

Tay, A. K., Rees, S., Steel, Z., Liddell, B., Nickerson, A., Tam, N., \& Silove, D. (2016). The role of grief symptoms and a sense of injustice in the pathways to post-traumatic stress symptoms in post-conflict Timor-Leste. Epidemiology and Psychiatric Sciences, 1-11. https://doi.org/10.1017/S2045796016000317

Tilly, C. (2006). Why? Princeton, NJ: Princeton University Press.

Tol, W. A., Komproe, I. H., Thapa, S. B., Jordans, M. J., Sharma, B., \& De Jong, J. T. (2007). Disability associated with psychiatric symptoms among torture survivors in rural Nepal. Fournal of Nervous and Mental Disease, 195(6), 463-469. https://doi. org/10.1097/NMD.0b013e31802f5dac

Van Ommeren, M., de Jong, J. T., Sharma, B., Komproe, I., Thapa, S. B., \& Cardena, E. (2001). Psychiatric disorders among tortured Bhutanese refugees in Nepal. Archives of General Psychiatry, 58(5), 475-482. http://dx.doi.org/10.1001/ archpsyc.58.5.475

Wemmers, J. A., \& Manirabona, A. (2014). Regaining trust: The importance of justice for victims of crimes against humanity. International Review of Victimology, 21(1): 101-109. https://doi. org/10.1177/0269758013511163

Williams, B. (2008). Shame and necessity. Berkeley, CA: University of California Press.

Willis, S., Chou, S., \& Hunt, N. C. (2015). A systematic review on the effect of political imprisonment on mental health. Aggression and Violent Behavior, 25: 173-180. https://doi. org/10.1016/j.avb.2015.08.001

Wilson, J. P., Droždek, B., \& Turkovic, S. (2006). Posttraumatic shame and guilt. Trauma, Violence, \& Abuse, 7(2), 122-141. https:/doi. org/10.1177/1524838005285914

Wong, Y., \& Tsai, J. (2007). Cultural models of shame and guilt. In: Tracy, J. L., Robins, R. W., \& Tangney, J. P. (Eds.). The self-conscious emotions: Theory and research, (pp. 209-223). New York: Guilford Press.

Young, A. (1995). The Harmony of Illusions: Inventing Posttraumatic Stress Disorder. Princeton, NJ: Princeton University Press. 